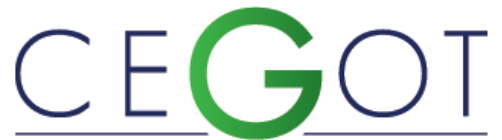

Centro de Estudos de Geografia e Ordenamento do Território
BORINELLI, BENILSON

Universidade Estadual de Londrina, Departamento de Administração

86050-981, Rodovia Celso Garcia Cid, s/n Km 377. Jardim Portal de Versalhes,

Londrina, Brasil

benilson@uel.br

\author{
GALLASSI, JULIANA \\ Universidade Estadual de Londrina, Departamento de \\ Administração \\ 86020-060, Londrina, Brasil \\ gallassi.juliana@gmail.com
}

MostagI, NICOLE

Universidade Norte do Paraná, Departamento de Administração 86010-150, Londrina, Brasil

nicole cerci@hotmail.com

Almeida, Dayane

Universidade Estadual de Londrina, Departamento de

Administração

86600-220, Rolândia, Brasil

day almeidac@hotmail.com

\section{COSTA, ROGÉRIO}

Universidade do Sul de Santa Catarina, Departamento de

Ciências Ambientais

88060-310, Florianópolis, Brasil

paralelosc46@gmail.com

\title{
(Des)ordem institucional e ordenamento territorial: considerações sobre a política ambiental de Goiás
}

Institutional (dis)order and territorial planning: Goiás' environmental policy considerations

Referência: Borinelli, Benilson et al. (2019). (Des)ordem institucional e ordenamento territorial: considerações sobre a política ambiental de Goiás. Revista de Geografia e Ordenamento do Território (GOT), n. ${ }^{\circ} 16$ (março). Centro de Estudos de Geografia e Ordenamento do Território, p. 5-27, dx.doi.org/10.17127/got/2019.16.001

\section{RESUMO}

Analisamos as relações entre desordem institucional da política ambiental e ordenamento territorial capitalista, por meio de um estudo de caso qualitativo e exploratório-descritivo em Goiás (Brasil). Destacando o papel do Estado e apoiados na premissa de ocupação capitalista contraditória do território, procuramos pensar a política ambiental estadual como uma expressão da dialética ordem-desordem. O declínio orçamentário, a instabilidade e a retração institucional da política ambiental deram-se em um momento de expressiva expansão econômica e prolongado domínio político de uma frente de centro-direita e direita e pouco sensível às demandas ambientais. Enquanto expressão de relações de forças históricas, a política ambiental, embora marginal e errática, ganha relevância políticoinstitucional ao viabilizar e legitimar a apropriação dos recursos naturais e a externalização 
de impactos e custos socioambientais segundo formas particulares de ordenamento capitalista.

Palavras-chave: Desordem institucional, Ordenamento territorial, Política ambiental, Estado, Estado de Goiás

\section{ABSTRACT}

In this qualitative and exploratory-descriptive case study, we analyze the relations between institutional disorder of environmental policy and capitalist territorial planning in Goiás (Brazil). Stressing the State's role and supported by the contradictory capitalist territory's occupation premise, we try to think about state's environmental policy as an expression of the order-disorder dialectic. The budgetary decline, the instability and the institutional retraction of environmental policy took place at a moment of significant economic expansion and prolonged centre-right and right front political dominance, less sensitive to environmental demands. As an expression of historical forces relations, environmental policy, although marginal and erratic, gains political-institutional relevance by enabling and legitimizing the natural resources' appropriation and the externalization of socioenvironmental impacts and costs according to particulars forms of capitalist's territorial planning.

Keywords: Institutional disorder, Territorial planning, Environmental policy, State, State of Goiás.

\section{Introdução}

Desde os anos 1970, influenciada por tendências e mudanças internacionais, a política ambiental passou a interferir mais sistematicamente nos processos de produção, ordenamento e transformação dos territórios no Brasil. Desde então ficou mais evidente que as diversas instâncias do Estado deveriam lidar com a tarefa, muitas vezes contraditória, de, ao mesmo tempo, promover a proteção ambiental e a expansão econômica em moldes capitalistas.

A crescente institucionalização das políticas ambientais nos anos 1980 e 1990 (NEDER, 2002) contou com a forte presença dos estados brasileiros, os quais assumiram um papel proeminente nesse campo por suas atribuições constitucionais, maior disponibilidade de recursos e de poder político em escala regional. Os estados federados, pela maior proximidade e conhecimento das características e problemas ambientais, podem oferecer políticas mais efetivas e inovadoras. Ainda assim, os constrangimentos estruturais do Estado 
na esfera estadual ${ }^{1}$ e a maior vulnerabilidade às forças políticas e econômicas regionais tendem a restringir o campo de ação e a participação das e nas políticas ambientais, quando tomadas normativamente em seus preceitos legais e administrativos (HAY, 1994; DAVIDSON; FRICKEL, 2004).

Procurando chamar a atenção para as possíveis formas de mediação que o Estado, observadas principalmente através da política ambiental, exerce na transformação do território em sociedades capitalistas, neste artigo analisamos as relações entre desordem institucional da política ambiental e o ordenamento territorial capitalista no estado de Goiás. Profundas transformações ocorreram no território goiano desde os anos 1960 para torná-lo uma das maiores economias do país e referência do modelo de moderno agronegócio capitalista. Porém, esta dinâmica ocasionou grandes mudanças socioambientais como a homogeneização econômica e cultural do território, e as resultantes da destruição do cerrado, substituído por pastagens, bem como o uso intensivo de agrotóxicos (OLIVEIRA; CHAVEIRO; OLIVEIRA, 2009).

Seguindo uma tendência nacional, Goiás instalou o seu primeiro aparato administrativo ambiental em 1975 em resposta a um conjunto de problemas relacionados à preservação do meio ambiente. Contudo, após esforços para fortalecer e consolidar a política ambiental estadual nos anos 1980 e 1990, dados oficiais da Secretaria do Tesouro Nacional (STN) indicam uma queda expressiva nos gastos ambientais dessa unidade entre 2002 e 2013, a segunda maior entre os estados (GUANDALINI, 2016). Além disso, a instabilidade institucional, déficits da política ambiental e denúncias de corrupção, reconhecidos pelos próprios governos, comporiam um quadro que estamos denominando aqui de desordem institucional. Esse declínio, iniciado no começo da década de 2000, como pretendemos demonstrar, sugere uma configuração particular das relações de forças políticas e econômicas, na qual a política ambiental pode ser entendida como condição e produto de uma forma particular de ordenamento do território. Dado o caráter excepcional e provavelmente paradigmático desse caso, ele pode ser de grande importância para o estudo de possíveis tendências nas políticas ambientais estaduais brasileiras.

\footnotetext{
${ }^{1}$ Para evitar confusões entre o Estado como instituição política e como unidade federativa, embora assumamos as duas condições necessariamente inerentes ao fenômeno, convencionamos nominar o primeiro com "e" maiúsculo e, o segundo, com "e" minúsculo.
} 
A análise das interações entre desordem institucional da política ambiental e o ordenamento territorial capitalista foi desenvolvida por meio de um estudo de caso qualitativo, exploratório-descritivo do estado de Goiás entre 2002 e 2013. Partindo de uma perspectiva histórica e crítica, abordamos as relações entre essas duas categorias apoiados na premissa de ocupação capitalista contraditória do território que tem no Estado, com destaque para a política ambiental estadual, uma das expressões da dialética ordemdesordem, que tende a caracterizar as formas possíveis de mediação política e econômica nas relações entre sociedade capitalista e natureza. Assim, o Estado, sobretudo em suas funções executiva e legislativa, é tomado, ao mesmo tempo, como a expressão de relações de forças temporal-espaciais e um espaço estratégico-relacional disputado por projetos territoriais que, em regra, reproduzem relações capitalistas marcadas por desigualdades institucionais e socioambientais.

Este trabalho pretende contribuir para o maior conhecimento dessa experiência com base em uma leitura crítica que destaca as possíveis relações entre o ordenamento territorial e a política ambiental estadual. Não pretendemos apresentar um estudo exaustivo dessas relações, sobretudo pela complexidade inerente a esses dois temas, nem promover a avaliação sistemática de um programa ambiental específico ou mesmo da política ambiental estadual. Buscamos apontar algumas confluências institucionais, econômicas e políticas que, no seu conjunto, podem contribuir para compreensão das tensões, contradições e resultados institucionais da política ambiental em suas interações com o ordenamento territorial. Dessa forma, procuramos realizar um esforço para fazer uma primeira aproximação dessas interações de modo a contribuir com as reflexões sobre o papel do Estado, e particularmente da política ambiental, no processo de ordenamento territorial capitalista.

Este artigo se divide em cinco partes. Inicialmente discutimos as bases teórico-conceituais que orientaram a construção do estudo e, em seguida, expomos os procedimentos metodológicos. Posteriormente, apresentamos as evidências da desordem institucional da política ambiental em Goiás e as principais forças condutoras do ordenamento territorial no estado. Depois disso, destacamos algumas considerações sobre a relação entre a desordem institucional e o ordenamento territorial na configuração da política ambiental goiana. Por fim, evidenciamos os limites da pesquisa e pontuamos áreas e temas para futuras pesquisas. 


\section{Considerações sobre Estado, política ambiental e ordenamento territorial}

Enquanto condensação de uma relação de forças, histórica e espacialmente situado, o Estado é um espaço estratégico-relacional fundamental para reprodução das relações sociais capitalistas (JESSOP, 2016). Suas instâncias executivas, legislativas e judiciárias precisam lidar continuamente com o problema de conciliar, legal e extralegalmente, e legitimamente o aparato jurídico e de direitos instituídos às dinâmicas e mutações de princípios imperativos da propriedade privada, relações de troca e da mercantilização do trabalho e dos recursos naturais, com a subordinação da natureza à lógica inerentemente expansionista e acumuladora do capital.

Entendemos o território como um espaço de exercício de poder, que na sociedade moderna apresenta-se como um domínio basicamente centralizado no Estado (MORAES, 2000). Sendo assim, o território é qualificado pelo domínio político de uma dada superfície terrestre. Ou seja, território é uma entidade histórica, que expressa o controle social do espaço por uma dominação jurídico-política institucionalizada, no caso das sociedades contemporâneas, subordinada, em grande medida e contraditoriamente, a um ordenamento territorial de orientação capitalista. Assim, o ordenamento territorial seria: "[...] uma forma singular de uso do território que apresenta um arranjo de objetos sociais, naturais e culturais historicamente estabelecidos. Mas esse ordenamento não é apenas condição social de reprodução da ordem capitalista. É também reflexo de sua significação funcional e simbólica na totalidade social capitalista" (SILVA, 2011, p. 297). Desta forma, é estabelecido "por meio de um campo de forças com o poder centralizador do Estado, desejoso de impor de cima um modelo de organização fundamentado no controle e domínio do espaço" (DOMINGUES, 2015, p. 52-53).

$\mathrm{Na}$ forma de ordenamento territorial baseado na centralidade capitalista, o objetivo é "conter e manter os conflitos [e contradições entre espaços e contra-espaços] em limites administráveis, instaurando, por meio de regras e normas de regulação, um quadro de relação societária alicerçado na hegemonia política das classes que dão a referência do centro" (MOREIRA, 2011, p. 77). 
Desde o início, as políticas ambientais vão se impor como um tipo de demanda por regulamentação estatal e social sobre as formas usuais de apropriação dos recursos e sistemas naturais e suas consequências negativas (externalidades): para os seres humanos, para outras espécies e para o equilíbrio ecológico. Formal e administrativamente, a política ambiental é reconhecida por um conjunto de legislações, instituições e recursos que o poder público mobiliza para reduzir os conflitos e cumprir sua responsabilidade de assegurar as condições naturais para a produção, circulação e consumo econômicos. Contudo, a política ambiental, enquanto extensão especializada da ação estatal, precisa também ser entendida, em especial o seu desempenho político, como expressão do resultado das relações de forças sociais cuja referência de ação e não ação segue as coordenadas econômicas, políticas, culturais e ambientais definidas histórica e espacialmente (BORINELLI, 2007).

Tomada em uma dimensão crítica, a política ambiental do Estado capitalista assumiria três principais funções gerais: favorecer a expansão e a valorização de capitais segundo as expectativas e padrões de transformação territorial de seus agentes, desmobilizar e neutralizar forças identificadas como anticapitalistas e legitimar as decisões e efeitos contraditórios das duas primeiras funções. Em resumo, a contradição geral e ao mesmo tempo principal tarefa do Estado, por meio da política ambiental, mas não só, seria fomentar e restringir legitimamente, sob bases capitalistas e ambientais "sustentáveis", pelo menos no curto prazo, o crescimento (acumulação) econômico. Isso exigiria, em graus variados ao longo do tempo e do espaço, a necessidade de promover a desordem institucional - aqui entendida como a contenção e inviabilização da política ambiental especificada legal e administrativamente - como condição complementar às formas dominantes de uso do território. Dessa forma, os estados, como unidades subnacionais, participam diretamente da dialética ordem-desordem que move a dinâmica do processo de ordenamento e reordenamento territorial capitalista. Os estados são o principal centro de poder (força) legítimo subnacional, seja pela destacada capacidade de concentrar e distribuir recursos, seja pela sua função reguladora, e o seu controle é uma preocupação constante das forças econômicas e políticas regionais.

Como tal, o que esperamos demonstrar com o caso do estado de Goiás, é que essa dialética se reproduz em maior ou menor grau dentro do próprio aparelho estatal, em específico, na 
estrutura e funcionamento das instituições ambientais, como resultado de um pacto construído na base da sociedade civil. "As instituições são vistas como ordenadoras das ações políticas, portanto fazem parte do processo que oficializa medidas pensadas em determinado plano de ordenamento territorial" (DOMINGUES, 2015 p. 57). Como instituição que expressa a estrutura e o perfil desse pacto entre forças econômicas e políticas, o Estado, desempenhando um papel articulacional dos arranjos espaciais, nos planos jurídicopolítico e ideológico-cultural (MOREIRA, 2011), necessita, para lidar com as suas atribuições contraditórias em relação ao meio ambiente, de níveis diferenciais de organização e efetividade de suas instituições (OFFE, 1984). É nesse sentido que a desordem institucional do setor ambiental pode ser entendida como a manifestação de uma contribuição essencial do Estado capitalista para o ordenamento territorial, na medida em que a sua ausência ou falha constituem um dos principais mecanismos seletivos e estratégicos para repelir medidas de proteção ambiental percebidas como ameaçadoras ao avanço capitalista (SWEEZY, 2004).

\section{Aspectos metodológicos}

Para auxiliar na correlação das confluências institucionais, econômicas e políticas que, em seu conjunto, podem contribuir para a compreensão das relações entre a desordem institucional da política ambiental e o ordenamento territorial em Goiás, realizamos um estudo de caso qualitativo, longitudinal e de caráter exploratório-descritivo. O recorte temporal foi de 2002-2013, período para o qual existiam dados sobre os gastos em gestão ambiental do estado disponíveis na base da Secretaria do Tesouro Nacional no momento da realização da pesquisa. Foram coletados dados, sobretudo entre novembro de 2015 e março de 2016, de três principais fontes: artigos, livros e periódicos sobre a história política, ambiental e econômica de Goiás, documentos oficiais (dados orçamentários, relatórios e legislações), e entrevistas com especialistas na política ambiental goiana.

Os dados sobre gastos ambientais foram extraídos das bases do STN e do Portal da Transparência de Goiás, e, os valores monetários, atualizados pelo Índice IGP-DI da Fundação Getúlio Vargas para dezembro de 2013. Três categorias centrais orientaram nossa 
estratégia de pesquisa: a desordem institucional, o ordenamento territorial e o contexto político. A desordem institucional do setor ambiental foi captada pelas variações absolutas e proporcionais do orçamento ambiental, instabilidade e fragilidade institucional; o ordenamento territorial, pelas principais transformações indicadas pelo crescimento econômico, modelos produtivos dominantes e seus decorrentes impactos ambientais; o contexto político, pela composição partidária e ideológica dominante nos poderes executivo e legislativo durante o período de análise. Dados quantitativos e qualitativos foram articulados, lançando mão da análise de conteúdo e da triangulação, de forma a permitir uma avaliação abrangente e complexa de diferentes fenômenos, dados empíricos, análise do contexto e da visão de vários informantes (MINAYO, 2001).

\section{Crise da política ambiental, economia e política em Goiás}

O estado de Goiás está localizado no Planalto Central, região Centro-Oeste brasileira, e ocupa uma área de $340.086 \mathrm{~km}^{2}$, quase completamente coberta pelo bioma do cerrado. Esse bioma se destaca pela riqueza de espécies que possui, considerado como uma das vegetações mais ricas em biodiversidade (GOIÁS, 2015).

Legitimado na ideologia da Marcha para o Oeste, a fim de modernizar o estado e inseri-lo na lógica da economia capitalista, a ocupação territorial de Goiás resultou de interesses políticos e econômico claramente delineados (OLIVEIRA; CHAVEIRO; OLIVEIRA, 2009). A ocupação capitalista intensiva do território no estado iniciou, de fato, na década de 1960, incentivada pelas riquezas naturais da região, relevo adequado à mecanização e posição geográfica, contando com fortes incentivos governamentais para o financiamento da expansão de suas fronteiras agrícolas. A partir da década de 1970, as políticas desenvolvimentistas geraram transformações econômicas e demográficas, fruto do deslocamento intenso da população rural aos centros urbanos, delineando um novo ordenamento territorial (IMB, 2016). Nesse período, a paisagem goiana converteu-se rapidamente de uma paisagem natural para um cenário agrícola, transformando o território em grandes plantações e monoculturas empresariais, com uso do cerrado para fins produtivo e lucrativo (OLIVEIRA; CHAVEIRO; OLIVEIRA, 2009). 
Em contrapartida, a degradação ambiental em grande escala fez-se sentir na devastação desse bioma, na compactação do solo, na erosão, na contaminação da água e na perda de biodiversidade (DELLA GIUSTINA, 2013). A evidência desses problemas no território goiano e a proeminência das discussões ambientais internacionais nos anos 1970 levaram à inserção desta pauta na agenda política do estado, culminando na criação da primeira estrutura ambiental, a Superintendência Estadual do Meio Ambiente de Goiás (SEMAGO) em 1975 (CHAVES, 2003).

Com o retorno das eleições diretas para governador, em 1982, teve início o ciclo de governo do PMDB (Partido do Movimento Democrático Brasileiro), encerrado em 1998. Nesse período, após várias reformas institucionais, o setor ambiental conquistou o importante destaque na estrutura estatal contando com uma Secretaria de Meio Ambiente e Recursos Hídricos (SEMARH) e com um órgão executivo Fundação Estadual do Meio Ambiente (FEMAGO) (CHAVES, 2003).

Em 1999, um novo grupo político liderado pelo PSDB (Partido da Social Democracia Brasileira) assumiu o poder executivo de Goiás, permanecendo no poder até hoje (2017). Esse período foi marcado pela centralização, instabilidade e desinvestimento no setor ambiental. Já em 1999 a FEMAGO foi substituída pela Agência Goiana de Meio Ambiente e Recursos Naturais, que foi extinta em 2009, com suas atribuições sendo incorporadas pela SEMARH. A partir de então, a política ambiental de Goiás passou a ser gerida por uma estrutura centralizada, com o planejamento e a execução das políticas concentradas em um único órgão localizado na capital do estado (CHAVES, 2003). Em 2016, o setor ambiental perdeu mais espaço político com a extinção da SEMARH e a criação de uma pasta multitemas, a Secretaria de Meio Ambiente, Recursos Hídricos, Infraestrutura, Cidades e Assuntos Metropolitanos (SECIMA).

Outra evidência da fragilização da política ambiental goiana nesse último período pode ser constatada no comportamento orçamentário do setor ambiental estadual. 


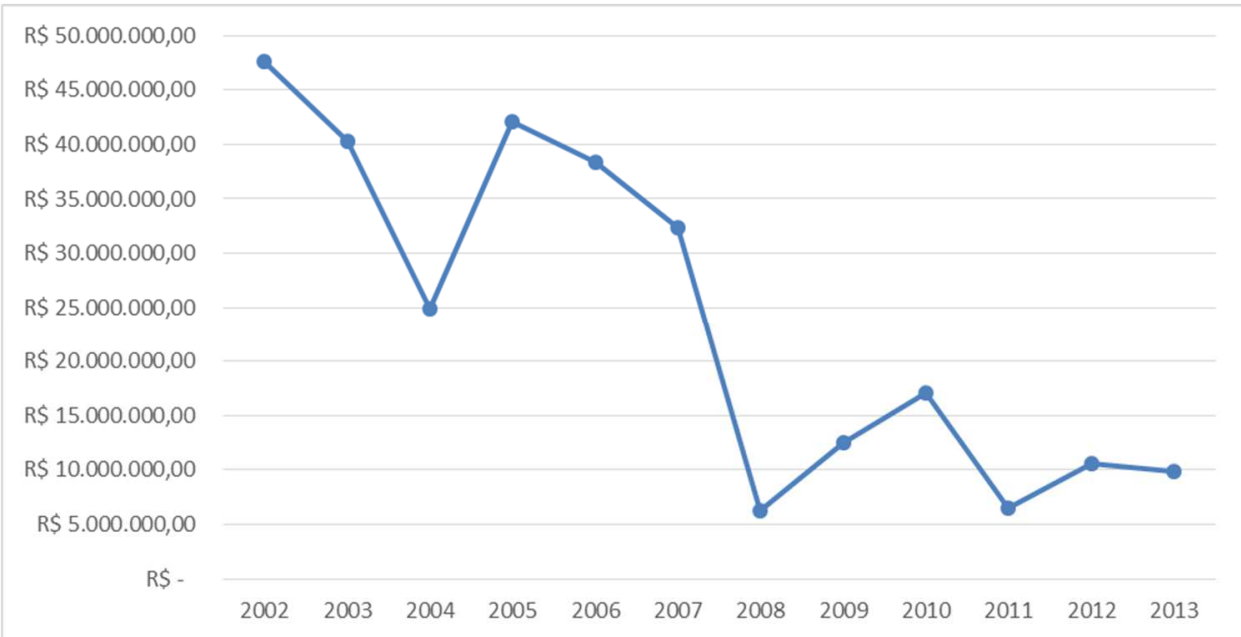

Gráfico 1 - Gasto absoluto da função “Gestão Ambiental” em Goiás no período de 2002 a 2013. Fonte: GALLASSI (2016), com base em dados do STN.

Entre 2002 e 2013, o gasto na função Gestão Ambiental reduziu de 47 milhões para 9 milhões, uma retração de aproximadamente $80 \%$ (Gráfico 1). A participação dos gastos ambientais no gasto total do estado caiu de $0,46 \%$, em 2002 , para $0,05 \%$, em 2013. Embora esteja em $9^{\circ}$ lugar no ranking nacional dos estados mais ricos, segundo o PIB de 2014, Goiás aparece na $21^{\circ}$ posição quando considerada a média dos gastos ambientais absolutos dos estados brasileiros entre 2002 a 2012. No mesmo período, a participação proporcional média dos gastos ambientais no gasto total de Goiás foi a segunda pior entre os estados brasileiros (GUANDALINI, 2016).

A insuficiência de recursos e a carência de profissionais qualificados interferiu nas atividades de rotina, como emissão de licenças ambientais, controle, fiscalização, produção de informações sobre a qualidade ambiental e manutenção das Unidades de Conservação (UC), as quais sofrem com a ausência de fiscalizações e de apoio governamental para mantê-las (ENTREVISTADO 2, 2016). O auge da crise do setor aparenta ter ocorrido ao final de 2010, quando a baixa remuneração, as precárias condições de trabalho e a inexistência de planos de carreiras culminou, em 2016, na vacância de 100 cargos na área ambiental da SECIMA, situação que ocasionou diversos atrasos e acúmulo de atividades na secretaria (FOLHA DO SUDOESTE, 2017). Além disso, na última década, tornaram-se cada vez mais frequentes as denúncias de corrupção envolvendo os agentes de fiscalização do órgão ambiental de Goiás na liberação de licenças e autorizações para desmatamento (JORNAL OPÇÃO, 2017). 
Se a descontinuidade e declínio da política ambiental - situação denominada aqui de "desordem institucional" - pode ser considerada enquanto desempenho do Estado como resultado das relações de forças econômicas e políticas na base da sociedade, torna-se necessária uma abordagem mais detida sobre o caráter das forças dominantes na transformação do território goiano no período analisado.

Com base no entendimento de que "[...] o território é o produto de uma relação desigual de forças, envolvendo o domínio ou controle político-econômico do espaço e sua apropriação simbólica, ora conjugados e mutuamente reforçados, ora desconectados e contraditoriamente articulados" (HAESBAERT, 2004, p. 121), será discutido o ordenamento territorial em Goiás enquanto uma disputa de território, considerando o conjunto de relações histórico-sociais e suas implicações na relação entre os processos sociais e o espaço material.

Excluindo Brasília, Goiás é a maior economia e a mais industrializada das regiões CentroOeste e Norte. Foi o primeiro estado da região a modernizar a produção agrícola e criar as condições de instalação de um setor industrial integrado ao setor agropecuário (MONTEIRONETO; ROMANATTO, 2015). A partir da década de 1990, sua economia apresentou desempenho econômico positivo, alcançando resultados superiores às médias registradas em outros estados, com taxas de crescimento acima da média nacional. De 2000 a 2010, o Produto Interno Bruto (PIB) goiano ( $R \$ 97,5$ bilhões em 2010) quase duplicou a cada quinquênio. Seu progresso econômico é fruto de investimentos privados e apoio do governo em setores industriais, com destaque às atividades agropecuárias voltadas para a produção de commodities (GOIÁS, 2015).

Com uma economia alicerçada no uso da terra, uma porção expressiva de seu PIB, cerca de $60 \%$, resulta do agronegócio. Na agricultura, a produção de grãos, oleaginosas e fibras aparece com maior expressão, figurando em 4일 lugar no ranking nacional da produção de grãos, em 2015. Na pecuária, destaca-se nacionalmente na criação de bovinos, com significativa ascensão na criação de aves e suínos desde a vinda da empresa Perdigão S.A. em 1998 (IMB, 2016). Nessa mesma década, além da agroindústria, novos setores industriais começaram a ganhar força, como a fabricação de produtos químicos, produtos farmacêuticos, veículos automotores e a produção de etanol (IMB, 2016). 
Os resultados dessas transformações recentes no território geraram novos e aprofundaram prejuízos ambientais já existentes. O mais grave é a destruição do cerrado, causado principalmente pelas atividades agropecuárias modernizadas. Estima-se que aproximadamente $90 \%$ deste bioma esteja alterado, com alto risco de sua recomposição ser irreversível (FREITAS, 2016). O estudo realizado pelo Instituto Brasileiro de Geografia e Estatística (IBGE) revela que as matas nativas em Goiás reduziram drasticamente entre 1985 e 1995, de 10,78\% do território para 0,30\% (AGÊNCIA AMBIENTAL DE GOIÁS, 2001). Dados da World Wide Foundation (WWF) calculam que $60 \%$ do cerrado goiano foi substituído por pastagens, $6 \%$ pela agricultura, $14 \%$ pela ocupação urbana e apenas $19 \%$ está conservado, sendo que somente 1\% está em Unidades de Conservação (FREITAS, 2016). Além disso, em 2011, Goiás estava entre os cinco estados brasileiros que ofereciam maior risco de contaminação por agrotóxicos, devido à utilização intensiva de defensivos agrícolas, e, um ano depois, foi classificado como o segundo estado brasileiro que mais faz uso de agrotóxicos (GLOBO RURAL, 2015).

Assim, a expansão econômica recente em Goiás, ainda que não sem resistência, resultou de um processo histórico de produção de seu território segundo uma lógica predominantemente orientada para a expansão do agronegócio. O declínio da política ambiental favoreceu o avanço de atividades produtivas que, em sua própria dinâmica, dependem da expansão territorial. Embora não seja possível afirmar que o ordenamento territorial e a desordem institucional estejam diretamente conectados, buscamos realçar que não há um lado estático e outro dinâmico, ambos correspondem à ordem e à desordem, como se o conflito fosse condutor das mudanças e também da estabilidade (MOREIRA, 2011).

A ausência ou fragilidade regulatória do Estado, pela falta de fiscalização, monitoramento e acompanhamento da política ambiental, tanto favorece e legitima quanto é um efeito requisitado e dependente da influência política dos atores econômicos. Sendo o Estado, como defende Jessop (2016), um espaço estratégico a ser conquistado por forças econômicas e sociais, na medida em que é por meio dele que se procura influenciar os seus instrumentos de poder, suas instituições, políticas e orçamento, resta discorrer sobre algumas evidências de como se configurou esse processo em Goiás. 
Falar da dimensão política é falar sobretudo das relações de forças que marcam o acesso e uso seletivo e estratégico dos aparelhos estatais em suas funções fiscal, regulatória, ideológica e repressiva. Não caberia aqui um inventário completo dessas relações no caso estudado, nem sobre como se movem contraditoriamente em cada uma dessas faces, mas faremos abaixo uma breve descrição geral dessas forças ao longo de um período recortado, para, em seguida, tecer alguns comentários sobre as prováveis repercussões desse quadro geral para a "desordem" nas políticas ambientais.

Desde o retorno das eleições para governador em 1982, Goiás vem sendo um estado de pouca alternância de partidos no poder executivo, com o predomínio de siglas que podem ser identificadas ideologicamente como de centro-direita e de direita (TAROUCO; MADEIRA, 2015). Entre 1982 e 1999 foram eleitos apenas governadores do PMDB e, após 1999, o PSDB vem controlando o poder executivo, com exceção do intervalo de 2006 a 2011, quando o Partido Progressista (PP), em coligação com o PSDB, esteve à frente do governo estadual. Das cinco últimas eleições para governador, Marconi Perillo (PSDB) saiu vencedor em quatro delas. PP e PSDB estão mais alinhados a uma ideologia neoliberal, a qual tende a desconsiderar a questão ambiental ou a dar-Ihe pouca importância. O programa partidário do PSDB nacional, por exemplo, não trata de questões ambientais em sua agenda (BARROS, 2015).

No poder legislativo, de 1999 a 2014, os partidos com ideologias de centro, centro-direita e direita detiveram, em média, $72,3 \%$ das cadeiras. Em geral, eram partidos considerados desenvolvimentistas e preservacionistas, ambos defensores da subordinação das questões ambientais ao crescimento econômico. Os partidos classificados como de esquerda, os quais poderiam ser mais propensos a maior controle ambiental estatal (BARROS, 2015), representaram em média $15 \%$ das cadeiras no legislativo no mesmo período. Houve, assim, tanto à frente do executivo como predominantemente do legislativo, a dominância de partidos que tendem a considerar em menor grau questões ambientais ou mesmo a assumir posições antiambientalistas.

Tanto na casa legislativa estadual quanto na federal, o agronegócio goiano tem forte representação e alto grau de mobilização. No contexto nacional, PSDB e PMDB são partidos cujos políticos possuem as maiores quantidades de terras declaradas no Tribunal Superior Eleitoral. No Congresso Nacional, a bancada ruralista é uma das mais poderosas, seus 
deputados têm trabalhado para manter privilégios antigos, de um país agrícola (CASTILHO, 2012), liderando a defesa de pautas antiambientalistas, como a Reforma do Código Florestal, a flexibilização do licenciamento ambiental e o retrocesso na demarcação de terras indígenas. Em Goiás, entre 1999 e 2014, das atividades exercidas pelos parlamentares antes de ingressarem na legislatura estadual destacam-se aquelas relacionadas à agropecuária (21,09\%) e empresariais (17,03\%). No entanto, é a partir do ano de 2003 que fica mais evidente a predominância de deputados vinculados ao setor agropecuário, área que representa, historicamente, relevância no estado (MOTA, 2011). "Goiás tem vários grupos e o agronegócio é o mais forte, acho que a mineração também é forte, talvez não o mesmo peso da agricultura, mas também é forte" (ENTREVISTADO 2, 2016).

Embora a forma de ocupação espacial de Goiás desenvolvida até aqui tenha privilegiado os atores e instituições centrais das articulações e grupos hegemônicos e seus projetos, isso não deve eclipsar as recorrentes formas de resistência ao ordenamento territorial e, logo, à ação mediadora do Estado. Essa história dos "vencidos", projetos alternativos sub ou contra-hegemônicos e ações correspondentes, pode ser explicitada muito brevemente, em alguns episódios.

Durante a colonização de Goiás e, em seguida, com a exploração mineral, um primeiro enfrentamento deu-se com a invasão de terras indígenas (COELHO; BARREIRA, 2007). Os resultados desses conflitos exibiam a força econômica em face das tradições indígenas e das relações desiguais entre essas forças. Na atualidade, no estado existem apenas 8.583 índios, o que o classifica como a sexta unidade da federação com menor número de índios. Goiás é o segundo estado brasileiro com o menor número de índios em terras próprias, já que 96\% dos índios vivem marginalizados nas cidades (JORNAL O POPULAR, 2017), por isso a reinvindicação pela conquista e demarcação de suas terras como também pelo reconhecimento de sua identidade étnica pelo Estado (CASTRO, 1996) continuam atuais e cada vez mais urgentes.

O avanço da fronteira agrícola também encontrou resistência no movimento camponês em diversos momentos (COELHO; BARREIRA, 2007). Entre 1950 e 1957, a revolta de Trombas e Formoso, que teve a participação do Partido Comunista Brasileiro (PCB) organizando os trabalhadores rurais por meio das ligas de camponeses (DUARTE, 1998), foi um dos eventos mais emblemáticos desses movimentos de contraespaço em Goiás. 
A década de 1960, com a aprovação do Estatuto dos Trabalhadores Rurais (1963) e do Estatuto da Terra (1964), inaugurou a opção estatal por promover a "modernização" agrícola, e com isso, a restrição de acesso à terra pelos camponeses, intensificando a luta pela terra e pela reforma agrária (MARTINS, 1996). A partir da década de 1980, o Movimento dos Trabalhadores Rurais Sem Terra-MST consolidou-se como principal organização de luta pela terra e oposição ao grande latifúndio exportador (COELHO; BARREIRA, 2007), atuando em diversas frentes como: produção alternativa por cooperativas, invasão de terras e resistência. A luta camponesa pela terra em Goiás continua ativa, reivindicando a realização de vistorias para formação de assentamentos e arrecadação de terras para reforma agrária, além de melhoramentos para as famílias assentadas, como programas de assistência técnica e implementação de infraestrutura (CARTA CAPITAL, 2017).

Além dessas frentes de resistência, atualmente vários agentes e instituições se organizam e tentam confrontar o modelo hegemônico de ordenamento territorial em Goiás, como: Banco da Terra, Via Campesina, Comissão Pastoral da Terra (CPT), Movimento Terra Trabalho e Liberdade (MTL), Confederação dos Trabalhadores na Agricultura (CONTAG), Movimento de Libertação dos Sem-Terra (MLST), Federação dos Trabalhadores na Agricultura Familiar (FETRAF), MST/Organização dos Trabalhadores no Campo (OTC), Movimento Terra Livre (TERRA LIVRE), Democrático e Independente (TERRA LIVRE/MTL-DI) (DATALUTA, 2014).

Ainda que em situação quase sempre desfavorecida nas relações de forças intraestatais e com baixa recorrência, parte da resistência à desordem ambiental surge também de dentro do próprio Estado. Este pode ser o caso de segmentos ou pessoal de setores específicos de defesa ambiental, como o Ministério Público, do judiciário, ou mesmo de técnicos do setor ambiental, e, em nível federal, de instituições que atuam em Goiás, como Instituto Chico Mendes, Ministério Público Federal, IBAMA e Polícia Federal. Embora de forma nem sempre articulada e contínua, essas instituições podem ter um papel importante na resistência, sobretudo por meio da contestação e denúncia pontual de ilegalidades, de corrupção e dos riscos socioambientais dos projetos hegemônicos.

É claro que esses indícios não são conclusivos, nem podem explicar, isoladamente, todas as decisões, tensões e posições relacionados ao tema ambiental no período coberto por essa 
pesquisa. Contudo, o cenário descreve bem o contexto institucional e a configuração das forças que tinham mais poder para impor os seus conteúdos e interesses ao aparelho do Estado regional. Não bastasse isso, a dependência fiscal, econômica e política em relação à atividade econômica privada nas sociedades capitalistas tende a restringir e orientar consideravelmente as ações do Estado e do debate político em geral.

\section{Estado, política ambiental e território: esboço de uma síntese da experiência de Goiás}

Dado que o Estado é um espaço relacional e estratégico, os grupos dominantes não possuem um poder absoluto, nem deixaram de lidar com tensões e disputas entre eles e com outras forças contra-hegemônicas pelo controle político do espaço estatal ou em torno de projetos ideológicos e econômicos. Mas, como sugere certa unidade e perenidade do pacto político-ideológico hegemônico em Goiás, eles gozaram de grande poder de influência nos conteúdos seletivos das políticas públicas nesse período. Na condensação de forças que se expressa na sociedade política, os setores e funções estatais tendem a refletir os interesses gerais e contraditórios da reprodução capitalista nas políticas públicas que procuram sustentar diferencialmente o ordenamento territorial correspondente.

O acesso privilegiado ao aparelho do Estado permite usufruir com maior grau de liberdade e legitimidade dos fundos públicos, da máquina regulatória e de intervenção e da repressão oficial. A "articulação de fluxos tecnológicos e produtivos com a rede de poder legitima a ação de grupos" (SILVA, 2011, p. 309). Por outro lado, e simultaneamente, como bem demonstra a política ambiental, o controle da máquina pública permite restringir e inviabilizar demandas consideradas ameaçadoras. Desse modo, a dialética ordem-desordem implicada no ordenamento territorial capitalista estende-se para e parte de dentro do aparato do estado, erigido na dimensão político-administrativa da ação estatal (OFFE, 1984).

A desordem institucional na área ambiental, por meio, entre outras formas, da retração e instabilidade, da redução orçamentária, do desmonte do corpo técnico, da vulnerabilidade à corrupção e do retrocesso regulatório (evidenciado no caso das adequações do Código 
Florestal Estadual, menos restritivas do que o código federal reformado em 2012), aparecem como algumas das estratégias para neutralizar o potencial ameaçador das políticas ambientais, formando um ecossistema mais favorável (HARVEY, 2016) ao avanço capitalista sobre o território. A desregulamentação ambiental, ou o desmantelamento e recuo da interferência estatal, não apenas dá mais autonomia para os atores de mercado (CASTREE, 2008), sinalizando positivamente com menos restrições ao uso do território para os atuais e futuros investimentos, mas também é um requisito para a competição econômica e política entre forças políticas e os estados.

No caso de Goiás, é interessante como esses grupos contribuíram e contribuem para a construção da própria identidade do estado como território modelo da moderna produção agroindustrial. Assim sendo, o Estado goiano, em seu papel articulacional (jurídico-político e ideológico-cultural) (MOREIRA, 2011), expressa a estrutura e o perfil do pacto regional construído na base da sociedade civil em torno e liderada pelo projeto agroexportador expansionista.

Aqui é categórico isso [a influência de grupos de interesse econômico sob a formulação e implementação de políticas ambientais], porque o grande lobby contra a mudança do Código Florestal recentemente foi do agronegócio que tem uma liderança no estado de Goiás. Assim, não é ele o responsável, ele pegou essa brecha de você não ter uma política ambiental integrando o estado para, na verdade, quase que dizimar o que ainda restava do cerrado no estado, de aproveitar essas áreas. Óbvio que hoje, do ponto de vista econômico, traz recurso e sustenta boa parte da economia, mas há um prejuízo grande da parte ambiental sobre isso [...] eu acho que foi assim, uma necessidade de expansão do agronegócio com o enfraquecimento da política ambiental em Goiás (ENTREVISTADO 1, 2016).

O cenário descrito não tem a intenção de afirmar a inexorabilidade do desfecho produzido, mas a existência de um contexto institucional geral adverso que tornou possível uma política ambiental que refletiu, na maior parte do tempo, uma decrescente importância da pauta ambiental e o vigor de um antiambientalismo. Embora Goiás se destaque negativamente, sobretudo pela redução orçamentária, ele não é um caso isolado quando tratamos da fragilidade das políticas ambientais dos estados brasileiros (ABEMA, 2013). O declínio dos gastos dos estados na última década (GUANDALINI, 2016), a precarização das condições de trabalho e de controle ambiental dos seus órgãos, a tendência de desregulamentação ambiental, iniciada em 2010, sob governos de inclinação neoliberal, 
demonstram que fatores de um contexto mais amplo contribuíram para o quadro encontrado em Goiás.

Em que pese o capital e sua expansão perpétua dependerem de condições naturais adequadas, na maior parte do tempo essas condições ainda podem ser encontradas em políticas ambientais erráticas. Entretanto, a desordem institucional da gestão ambiental necessita administrar problemas decorrentes de suas próprias contradições. Apesar das contestações de setores da sociedade civil e do Estado (a exemplo do Ministério Público e órgãos federais), o acúmulo de problemas ambientais não parece gerar conflitos que não sejam administráveis (MOREIRA, 2011) ou mesmo ameaçar condições de reprodução de setores e atividades econômicas influentes. Ainda assim, evidências de graves problemas e o desconhecimento/descontrole ambiental tornam a temática ambiental e seus riscos futuros uma questão potencialmente explosiva e em aberto na agenda pública e que, portanto, devem ser negados ou amenizados recorrentemente. Não raro, a desordem ambiental, ou o acúmulo de riscos e problemas ambientais, desigualmente distribuídos, inerentes ao ordenamento capitalista, pode ser deslocada para o futuro e/ou para concepções de territorialidade concorrentes (contraespaço).

Apesar da legitimidade e relevância contra-hegemônica desses movimentos, eles têm sido insuficientes para se contrapor à forte influência das forças econômicas e políticas regionais, majoritárias nos poderes legislativo, executivo e judiciário, estadual e federal. Todavia, manter a desordem institucional em níveis aceitáveis requer algum esforço dado que tanto os governos quanto as atividades econômicas necessitam legitimar ambientalmente o ordenamento territorial.

Isso implica respostas mínimas às atribuições críticas, como emitir licenças ambientais e autorizações de desmatamento, pareceres, estudos em resposta a acidentes ambientais e crises pontuais, como as hídricas. Não raro o déficit legal-administrativo da política ambiental é enfrentado, em um clima de "gestão de crises", por meio de ações descontínuas, pontuais e desarticuladas, visando à reposição de legitimação de curto prazo. A pressão e os custos das demandas podem ser reduzidos, por exemplo, pela não produção/publicização de informações sobre a degradação ambiental, pela disseminação do discurso da sustentabilidade do agronegócio, pelo deslocamento de atribuições de controle ambiental para os agentes de mercado ou para instâncias locais do poder público, como 
vem sendo o caso da descentralização do licenciamento ambiental e da autorização de exploração florestal. Em Goiás, iniciado em 2006, o licenciamento municipal, mais sujeito às estruturas precárias dos municípios e aos interesses políticos e econômicos locais, reproduziu ou piorou em muitos aspectos a qualidade dos serviços prestados pelo órgão ambiental estadual (VIEIRA JÚNIOR; PASQUALETTO, 2011).

Em síntese, embora a trajetória e o contexto político e econômico em sociedades capitalistas como a goiana tendam, apesar da contínua contestação, a usar a desordem institucional como mecanismo seletivo para promover o ordenamento territorial, negando as suas consequências sociais e ambientais, isso não significa que a desordem ambiental esteja sob controle ou que a promoção da "ordem" se dê sem algum esforço, tensões e contradições. A tendência de o Estado privilegiar certos lugares por meio de estratégias de acumulação, projetos estatais e hegemônicos, o que Jones (1997) denominou de seletividade espacial, assume diversos arranjos ao longo do tempo e do espaço, mas talvez tenha em comum a propensão de promover, em diversas escalas, a injustiça, o desenvolvimento desigual e a inviabilização de projetos alternativos presentes e futuros pela "redução da natureza e da natureza humana à pura forma-mercadoria" (HARVEY, 2016, p. 243). Por isso mesmo, a contestação e a crítica ainda são necessárias para compreender e denunciar as conexões, contradições e os riscos inerentes às relações entre "desordem" política e reprodução/legitimação dos processos hegemônicos do ordenamento e reordenamento territorial capitalista.

\section{Considerações finais}

Procuramos discutir a política ambiental de Goiás destacando o papel do Estado no processo de ordenamento territorial. Tentamos apresentar a tese, apoiada na premissa de ocupação capitalista contraditória do território, de que a desordem institucional desta política tende a ter uma relação complementar ao ordenamento territorial vigente no período analisado. O estado goiano sobressaiu-se no cenário nacional, durante o período estudado, justamente por dar mostras de ter alcançado patamares bastante expressivos, talvez paradigmáticos, de desordem institucional da política ambiental. O declínio 
orçamentário, a instabilidade e retração institucional da política ambiental deram-se em um momento de expressiva expansão econômica e prolongado domínio político de uma frente de centro-direita e direita, pouco sensível às demandas ambientais, talvez mais bem descrita por um certo antiambientalismo. Isso demonstra, ainda que não sem tensões internas e contestação, a consistência social e ideológica do projeto de poder político e econômico do bloco, liderado pelo agronegócio, à frente do Estado goiano. Mesmo que não tenhamos demonstrado a existência de relações diretas entre a desordem institucional e o ordenamento territorial, afirmamos que essa desordem, seguindo a lógica da dialética ordem-desordem, vem favorecendo significativamente tal ordenamento. É claro, também, que isso não quer dizer que o quadro descrito seria o único possível, nem que perdurará no futuro.

Embora essa seja uma tendência relativamente lógica numa leitura do Estado capitalista, pode variar enormemente ao longo do espaço e do tempo em decorrência, entre outros fatores, da intensidade dos conflitos, da gravidade dos problemas ambientais, dos interesses, estratégias e capacidades em jogo. A política ambiental, nessa perspectiva, pode oferecer uma interessante leitura de uma determinada condensação de relações de forças que, estrategicamente, se expressa nas ações e não ações governamentais em torno da avaliação, regulamentação, autorização/licenciamento, fiscalização e legitimação das transformações nos territórios. Assim, ela pode ser interpretada como produto e produtora de relações de forças sociais assimétricas que conformam o processo de ordenamento territorial. As dinâmicas dos aparelhos do Estado, internas e nas relações com a sociedade civil, podem revelar a existência de um desempenho institucional diferencial e combinado.

Apesar de o uso analítico da ideia de desordem institucional remeter a um sentido aparentemente categórico, ele é extremamente relativo na realidade. Análises mais precisas necessitam considerar as diversas frentes da política ambiental (por exemplo, recursos hídricos, mudanças climáticas, devastação do cerrado, contaminação por agrotóxicos, conflitos socioambientais) e seus respectivos atores centrais, interesses, estratégias e conflitos em jogo. Por sua vez, considerar as interações entre dimensões econômicas, sociais, políticas, ambientais e culturais, em uma perspectiva histórica, como sugere a categoria do ordenamento territorial, é uma tarefa bastante complexa. Temos consciência de algumas das várias lacunas que não puderam ser abordadas neste trabalho, ainda assim 
esperamos que tanto elas quanto a exposição feita possam provocar discussões estimulantes e inspirar futuras pesquisas sobre as relações entre Estado, políticas ambientais e o ordenamento territorial.

\section{Referências bibliográficas}

ABEMA - ASSOCIAÇÃO BRASILEIRA DE ENTIDADES DE MEIO AMBIENTE. Novas propostas para o licenciamento ambiental no Brasil. Brasília, 2013.

AGÊNCIA AMBIENTAL DE GOIÁS. Estado Ambiental de Goiás - 2001. Goiânia, 2001.

BARROS, Antônio Teixeira de. Política partidária e meio ambiente: a adesão dos partidos políticos brasileiros à agenda verde. Opinião Pública, v. 21, n. 3, p. 693-733, dezembro 2015. ISSN 1807-0191.

BORINELLI, Benílson. Desempenho político-administrativo das instituições ambientais na década de 1990: a experiência da Fundação do Meio Ambiente de Santa Catarina - FATMA. Tese de Doutorado em Ciências Sociais, Instituto de Filosofia e Ciências Humanas, Universidade Estadual de Campinas, 2007.

CARTA CAPITAL. Trabalhadores Sem-Terra marcam ato em frente ao TJ-GO para pedir a liberdade de preso político [online]. 19 abril 2017 [Acesso em 6 dez. 2017]. Disponível em: http://justificando.cartacapital.com.br/2017/04/19/trabalhadores-sem-terra-marcam-ato-em-frente-ao-tj-gopara-pedir-a-liberdade-de-preso-politico

CASTILHO, Alceu Luiz. Partido da terra: como os políticos conquistam o território brasileiro. São Paulo: Editora Contexto, 2012. ISBN 978-85-7244-729-4.

CASTREE, Noel. Neoliberalising nature: the logics of deregulation and reregulation. Environment and planning A, v. 40, p. 131-152, 2008. ISSN 1472-3409.

CASTRO, O. M. Os Tapuia e a territorialidade: fortalecimento da consciência étnica. Revista de Divulgação Científica, Goiânia, n. 1, p. 25-37, 1996.

CHAVES, Manoel Rodrigues. Descentralização da política de meio ambiente no Brasil e a gestão dos recursos naturais no Cerrado Goiano. Tese de Doutorado em Geografia, Instituto de Geociências e Ciências Exatas, Universidade Estadual Paulista, 2003.

COELHO, José Braga; BARREIRA, Celene Cunha Antunes Monteiro. Esperança camponesa no estado de Goiás: a luta pela terra. Revista Educação e Mudança, n. 18-19, p. 1-16, 2007.

DAVIDSON, Debra; FRICKEL, Scott. Understanding Environmental Governance: A Critical Review. Organization \& Environment, v. 17, n. 4, p. 471-492, dez. 2004. ISSN 1552-7417.

DATALUTA. Banco de Dados da Luta pela Terra. Presidente Prudente, SP: FCT/ UNESP, 2014.

DELLA GIUSTINA, Carlos Christian. Degradação e Conservação do Cerrado: Uma história ambiental do estado de Goiás. Tese de Doutorado em Desenvolvimento Sustentável, Universidade de Brasília, 2013.

DOMINGUES, R. Ordenamento territorial, governança e a transposição de águas do São Francisco: uma perspectiva. Geografia e Ordenamento do Território, v. 8, p. 51-74, dez. 2015. ISSN 2182-1267.

DUARTE, E. G. Do mutirão à ocupação de terras: manifestações camponeses contemporâneas em Goiás. São Paulo. Tese de Doutorando em História Social, Faculdade de Filosofia, Letras e Ciências Humanas, Universidade de São Paulo, 1998.

FOLHA DO SUDOESTE. Governo de Goiás autoriza benefícios para servidores ambientais. 8 mar. 2017 [Acesso em 29 jul. 2017]. Disponível em: http://www.folhadosudoeste.jor.br/governo-de-goias-autoriza-beneficiospara-servidores-ambientais 
FREITAS, Eduardo de. Cerrado, um risco de extinção em Goiás. Brasil Escola. [Acesso em 25 jan. 2016 ]. Disponível em http://brasilescola.uol.com.br/brasil/cerrado-um-risco-extincao-goias.htm

GALLASSI, Juliana Nakamura. Política Ambiental no estado de Goiás: Uma análise a partir dos gastos na função gestão ambiental (2002-2013). 2016. Trabalho de Conclusão de Curso (Graduação em Administração), Universidade Estadual de Londrina, 2016.

GLOBO RURAL. Uso de agrotóxicos no Brasil cresce mais de duas vezes e meia em dez anos. 19 jun. 2015 [Acesso em 10 jul. 2017]. Disponível em: http://revistagloborural.globo.com/Noticias/noticia/2015/06/uso-deagrotoxicos-no-brasil-cresce-mais-de-duas-vezes-e-meia-em-dez-anos-1.html

GOIÁS. Secretaria de Estado de Gestão e Planejamento (SEGPLAN). Cenário Socioeconômico e Ambiental. 2015 [Acesso em 10 jul. 2017]. Disponível em: http://www.sgc.goias.gov.br/upload/arquivos/2015-04/estudo-docenario-socioeconomico-e-ambiental.pdf

GUANDALINI, Natália Nakay. Determinantes do gasto ambiental dos estados no Brasil: uma análise do período 2002-2012. 2016. Dissertação de Mestrado em Administração, Universidade Estadual de Londrina, 2016.

HAESBAERT, Rogério. O mito da desterritorialização: do "Fim dos Territórios" Multiterritorialidade. Rio de Janeiro: Bertrand Brasil, 2004. ISBN 8528610616.

HAY, Colin. Environmental security and state legitimacy. Capitalism Nature Socialism, v. 5, n. 1, p. 83-97, mar. 1994. doi: 10.1080/10455759409358577.

IMB - INSTITUTO MÁRIO BORGES. Estado de Goiás no contexto nacional - 2015. Goiânia, 2016.

JESSOP, Bob. The State: past, present, future. 1a ed. Cambridge: Polity Press, 2016. ISBN 0745633056.

JONES, M. R. Spatial Selectivity of the State? The Regulationist Enigma and Local Struggles over Economic Governance. Environment and Planning A, v29, n. 5, p. 831-864, 2015. ISSN 0308-518X.

KRAFT, Michael E. Environmental policy and politics. 5a ed. New York: Pearson Education, 2011. ISBN 0205745377.

MARTINS, José de Souza. O tempo da fronteira. Retorno à controvérsia sobre o tempo histórico da frente de expansão e da frente pioneira. Tempo Social, v. 8, n. 1, p. 25-70, maio 1996. ISSN 0103-2070.

MINAYO, Maria Cecília de Souza (Org.). Pesquisa Social. Teoria, método e criatividade. 18a ed. Petrópolis: Vozes, 2001. ISBN 85.326.1145-1.

MONTEIRO-NETO, Aristides; ROMANATTO, Eduiges (Orgs.). Capacidades governativas no ambiente federativo nacional: Goiás (2000-2012). Rio de Janeiro: Ipea, 2015. ISBN 978-85-7811-251-6.

MORAES, Antônio Carlos Robert. Bases da formação territorial do Brasil: o território colonial brasileiro no "longo" século XVI. 1a ed. São Paulo: Hucitec, 2000. ISBN 8527105284.

MOREIRA, Ruy. O espaço e o contraespaço: as dimensões territoriais da sociedade civil e do Estado, do privado e do público na ordem espacial burguesa. In: SANTOS, M.; BECKER, B. K. (Org.). Território, territórios: ensaios sobre o ordenamento territorial. 3. ed. Rio de Janeiro: Lamparina, 2011. p. 72-108.

MOTA, Regys Rodrigues. Mudanças e continuidades na elite parlamentar de Goiás: 1982-2010. 2011. Dissertação de Mestrado em Ciências Humanas, Universidade Federal de Goiás, 2011.

NEDER, Ricardo Toledo. Crise Socioambiental: estado e sociedade civil no Brasil (1982-1998). 1ạ ed. São Paulo: Fapesp, 2002. ISBN 8574192287.

OFFE, Claus. Problemas estruturais do Estado capitalista. 1a ed. Rio de Janeiro: Tempo Brasileiro, 1984. ISBN 1580120825343.

OLIVEIRA, Adão Francisco; CHAVEIRO, Eguimar Felício; OLIVEIRA, Ubiratan Francisco. Transformação em Goiás: Capitalismo, Modernização e Novas Disposições Socioespaciais. Caminhos de Geografia, v. 10, n. 32, p. 227234, 2009. ISSN 1678-6343.

SILVA, Carlos Alberto Franco. Fronteira agrícola capitalista e ordenamento territorial. In: SANTOS, M.; BECKER, B. K. (Orgs.). Território, territórios: ensaios sobre o ordenamento territorial. 3. ed. Rio de Janeiro: Lamparina, 2011. p. 282-312. 
SWEEZY, Paul M. Capitalism and the Environment. Monthly Review, v. 56, n. 4, out. 2004.

TAROUCO, Gabriela da Silva; MADEIRA, Rafael. Os partidos brasileiros segundo seus estudiosos: análise de um expert survey. Civitas, v. 15, n. 1, p. 24-39, jan./mar. 2015. ISSN 1519-6089.

VIEIRA JÚNIOR, Élio Jove; PASQUALETTO, Antônio. Análise da Descentralização do Sistema de Licenciamento Ambiental no Estado de Goiás. 2011. Trabalho de Conclusão de Curso (Graduação em Engenharia Ambiental), Pontifícia Universidade Católica de Goiás, 2011. 